\title{
Orofacial injuries and international rugby players' attitudes to mouthguards
}

\author{
P.J. Chapman, MB BS, MDS, FASMF \\ Department of Oral and Maxillofacial Surgery, University of Queensland Dental School, Brisbane, Australia
}

\begin{abstract}
This is the first such study of British rugby and the third yet published, the other two involving the 1984 Australian Wallabies and the 1987 United States Eagles. The report shows that while all 30 players believed mouthguards provided local protection, nine did not wear a mouthguard. Only one of the 21 who wore a mouthguard was willing to play without it, while eight mouthguard wearers felt mouthguards should be compulsory for adult rugby players. Twelve players had previously sustained an orofacial injury playing rugby which required treatment, only one of whom was wearing a mouthguard at the time. The full results are presented and compared with those of the previous two reports.
\end{abstract}

Keywords: Orofacial injuries, mouthguard usage, international rugby

It is generally accepted that there is a significant risk of sustaining dental and dentoalveolar injuries as well as intraoral and perioral lacerations when playing rugby ${ }^{1-5}$. Besides providing local protection which reduces the risk of sustaining such injuries, mouthguards reduce the likelihood of sustaining impact acceleration head injuries (concussion) following an impact to the mandible from below ${ }^{6,7,8}$. Mouthguards also provide some protection against condylar fractures. Therefore, mouthguards improve the safety of participants in rugby and other contact sports. Furthermore, professionally fitted vacuumformed mouthguards are considered to provide optimum protection and also have a much higher wearer acceptance level compared to either selfmoulded ('boil and bite') mouthguards or stock ('instant-wear') mouthguards ${ }^{4,7,8}$.

Mouthguards lessen the risk of concussion occurring subsequent to an impact to the mandible from below because the closed condylar position is approximately two $\mathrm{mm}$ further forwards than normal, reducing the level of force transmitted from the condyles to the base of the skull ${ }^{6,9,10}$. Also the level of force transmitted vertically through the midfacial skeleton will be reduced as some is absorbed as the

Address for correspondence: P.J. Chapman, Dept of Oral and Maxillofacial Surgery, University of Queensland Dental School,

Turbot Street, Brisbane 4000, Australia

(C) 1990 Butterworth-Heinemann Ltd

0306-4179/90/030156-03 lower teeth impact into the mouthguard. Therefore, mouthguards lessen the resultant violent head movement which subsequently occurs, and the acceleration forces to which the brain is subjected. Consequently, the risk of concussion is reduced following such an impact.

Figures 1 and 2 demonstrate the altered closed condylar position when a mouthguard is worn. Figure 1 shows the normal closed condylar position, and Figure 2 that when a mouthguard is worn. Note the increased distance between the condyle and the temporal bone in Figure 2.

The capacity of a mouthguard to attenuate impact forces depends on absorption of some of the energy by the material at the impact site, and subsequent distribution of the remaining energy throughout the mouthguard, that is, over a much larger surface area than the actual area of impact. Of course, with high level impact forces, these mechanisms are inadequate and injury will still occur, although it would not be nearly as severe as if a mouthguard had not been worn.

Only two other studies have investigated the prevalance of orofacial injuries (dental and dentoalveolar injuries, intraoral and perioral lacerations and fractures of the jaws) in international rugby teams. These were the 1984 Australian Wallabies and the 1987 United States Eagles ${ }^{1,2}$. Approval was obtained to conduct an identical study with the 1989 British Lions rugby team during their successful Australian tour to allow a comparison of their results with those of the two previous studies.

\section{Methodology}

A questionnaire was completed by the 30 members of the 1989 British Lions rugby team. This sought information about attitudes of players to wearing mouthguards as well as details of any orofacial injuries sutained when playing rugby which had required either dental or medical treatment. The questionnaire was identical to that used in the two previous studies.

\section{Results}

The results are presented in Table 1 together with the results obtained in the two previous studies. 


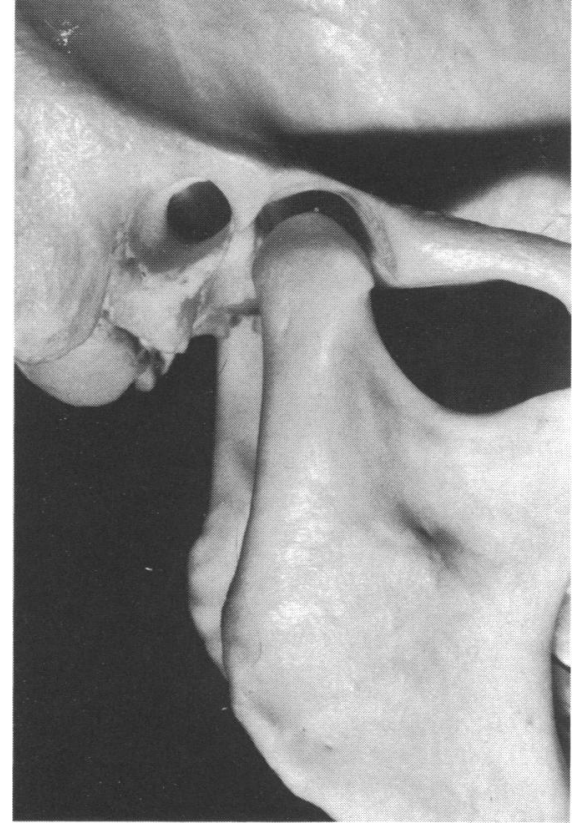

Figure 1. Using a skull on which the lateral wall of the glenoid fossa has been removed to demonstrate the normal closed condylar position

\section{Discussion}

Most of the results are similar to those of the previous studies except for the much lower percentage of mouthguard wearers in the British team who believed mouthguards should be compulsory in adult rugby.

All 30 members of the British team believed mouthguards provided local protection, and 21 wore a mouthguard of which 19 were professionally fitted. All nine who did not wear a mouthguard had previously done so. In four cases it was a professionally fitted mouthguard, and the five reasons given for

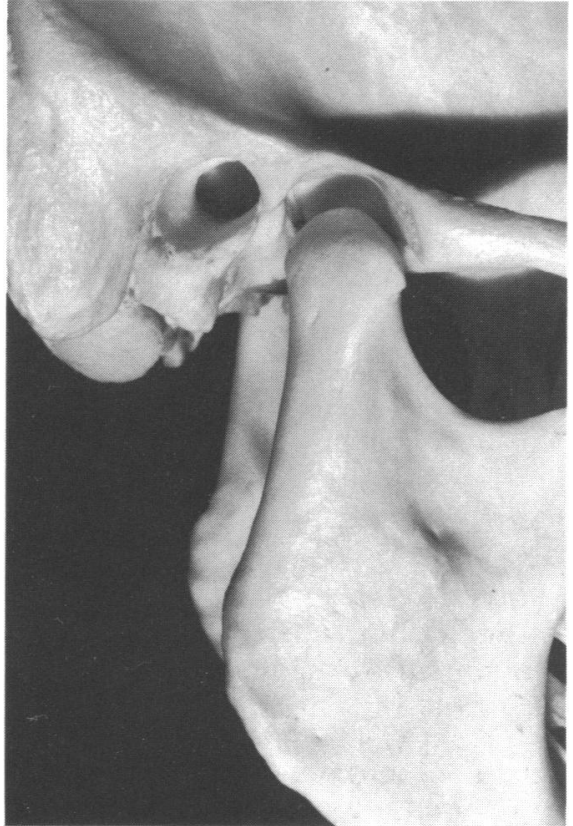

Figure 2. This demonstrates the closed condylar position when a mouthguard is in place

noncontinuance were: feeling of nausea and difficulty with speech by one player and, difficulty with breathing, dryness of mouth and lost mouthguard by one player each. Of the five who had tried to wear a self-moulded or stock mouthguard, the 13 reasons given for noncontinuance were: uncomfortable fit, difficulty with breathing and difficulty with speech by three players each, and feeling of nausea and dryness of mouth by two players each.

Of the 21 British team members who wore a mouthguard, 14 would be unwilling to play in a match without a mouthguard, another six would be very reluctant to play without it, while only one was

Table 1. The prevalence of orofacial injuries in inteernational rugby and players' attitudes to mouthguards - A study of the 1989 British Lions

\begin{tabular}{|c|c|c|c|}
\hline Question & $\begin{array}{c}\text { British } \\
\text { rugby team }\end{array}$ & $\begin{array}{c}\text { US } \\
\text { rugby team }\end{array}$ & $\begin{array}{l}\text { Australian } \\
\text { rugby team }\end{array}$ \\
\hline Average age & $26.8(20-32) y r$ & $29.7 \mathrm{yr}$ & $24.9 \mathrm{yr}$ \\
\hline Average number of years each player has played rugby & $14.9(8-24) \mathrm{yr}$ & $11.4 \mathrm{yr}$ & $13.6 \mathrm{yr}$ \\
\hline Percent who believe mouthguards provide local protection & $100 \%$ & $95.4 \%$ & $100 \%$ \\
\hline $\begin{array}{l}\text { Percent who wear a mouthguard } \\
\text { Average period each has worn a mouthguard }\end{array}$ & $\begin{array}{l}70 \% \\
12.6(1-20) y r\end{array}$ & $\begin{array}{l}50 \% \\
9.8 \mathrm{yr}\end{array}$ & $\begin{array}{l}80 \% \\
11.8 \mathrm{yr}\end{array}$ \\
\hline $\begin{array}{l}\text { Average delay from starting to play rugby before each started wearing a } \\
\text { mouthguard }\end{array}$ & $2.4(1-10) \mathrm{yr}$ & $1.8 \mathrm{yr}$ & $1.9 \mathrm{yr}$ \\
\hline Percent of mouthguards which were professionally fitted & $90.5 \%$ & $45.4 \%$ & $95.8 \%$ \\
\hline $\begin{array}{l}\text { Percent of mouthguard wearers who would: } \\
\text { not play without it } \\
\text { be very reluctant to play without it } \\
\text { be willing to play without it }\end{array}$ & $\begin{array}{r}66.7 \% \\
28.6 \% \\
4.8 \%\end{array}$ & $\begin{array}{l}90.9 \% \\
9.1 \% \\
0 \%\end{array}$ & $\begin{array}{r}37.5 \% \\
58.3 \% \\
4.2 \%\end{array}$ \\
\hline $\begin{array}{l}\text { Percent of wearers who believe mouthguards should be compulsory for } \\
\text { adult rugby players }\end{array}$ & $38.1 \%$ & $54.5 \%$ & $75 \%$ \\
\hline $\begin{array}{l}\text { Percent of team who had previously sustained an orofacial injury } \\
\text { requiring treatment }\end{array}$ & $40 \%$ & $36.4 \%$ & $33.3 \%$ \\
\hline
\end{tabular}


unconcerned. One player, Bob Norster, misplaced his mouthguard just prior to an international match and described the feeling throughout the match as a 'nightmare'. Eight of those wearing a mouthguard felt that mouthguards should be made compulsory for adult rugby players.

Twelve of the British team members had sustained an orofacial injury when playing rugby. Only one was wearing a mouthguard at the time and he sutained a laceration of the lower lip. This type of injury can occur regardless of whether a mouthguard is worn as the lower lip is usually torn on the lower anterior teeth. Injuries sustained by the other 11 were: fractured teeth (four players), avulsed (dislodged) teeth (two players), partially avulsed (luxated) teeth (two players), intraoral lacerations (one player), and unspecified dental injuries (two players). Eight of the 11 then started wearing a mouthguard, while another two tried but had difficulties and ceased. Of the eight specified dental injuries, in six cases the injury involved maxillary incisor teeth, in one case the injury involved a mandibular incisor and in the remaining case the injury involved two mandibular molars.

It has been discussed previously how mouthguards improve player safety in contact sports. Tomasin $e t a l$. have recently reinforced this view by stating that 'Although little equipment is used in rugby, all players should wear a protective mouthpiece. ${ }^{11}$, Another preventive aspect is the assessment of mandibular third molars as it has been experimentally shown that the presence of impacted third molars significantly weakens the mandible at the angle ${ }^{12}$. This in part accounts for the high incidence of such fractures resulting from contact sports ${ }^{13}$. For those involved in contact sports, prophylactic removal of impacted mandibular third molars should be arranged at about 18 years of age ${ }^{14}$.

Finally, when a team is planning an overseas tour it is recommended that all members have a dental examination and mouthguard inspection beforehand. Dental emergencies in foreign countries may pose practical problems, besides possibly incapacitating an individual for part of the tour.

\section{Acknowledgements}

The author is indebted to the 1989 British Lions team for their willing cooperation in this study which is sincerely appreciated, and to Dr L. B. C. Gilfeather, Team Medical Officer, for his interest and support.

\section{References}

1 Chapman, P.J. Orofacial injuries and mouthguards: A study of the 1984 Wallabies Brit J Sports Med 1985, 19, 93-95

2 Chapman, P.J. Players' attitudes to mouthguards and prevalence of orofacial injuries in the 1987 US rugby football team Amer J Sports Med 1989, 17, 690-691

3 Chapman, P.J. The prevalence of orofacial injuries and use of mouthguards in rugby union Aust Dent $J$ $1985,30,364-367$

4 Davies, R.M., Bradley, D., Hale, R.W., Laird, W.R.E. and Thomas, P.D. The prevalence of dental injuries in rugby players and their attitude to mouthguards Brit $J$ Sports Med 1977, 11, 72-74

5 Upson, N. Dental injuries and the attitudes of rugby players to mouthguards Brit J Sports Med 1982, 16, 241-244

6 Chapman, P.J. Concussion in contact sports and importance of mouthguards in protection Aust J Sci Med Sport 1985, 17, 23-27

7 Hildebrandt, J.R. Dental and maxillofacial injuries Clinics Sports Med 1982, 1, 449-468

8 Kerr, I.L. Mouthguards for the prevention of injuries in contact sports Sports Med 1986, 3, 415-427

9 Chapman, P.J. The pattern of use of mouthguards in rugby league Brit J Sports Med 1988, 22, 98-100

10 Hickey, J.C., Morris, A.L., Carlson, L.D. and Seward, T.E. Relation of mouth protectors to cranial pressure and deformation J Amer Dent Assoc 1967, 74, 735-740

11 Tomasin, J.D., Martin, D.F. and Curl, W.W. Recognition and prevention of rugby injuries Phys Sports Med $1989,17,114-126$

12 Reitzik, M., Lownie, J.F., Cleaton-Jones, P. and Austin, J. Experimental fracture of monkey mandibles Int J Oral Surg 1978, 7, 100-103

13 Schwimmer, A., Stern, R. and Kritchman, D. Impacted third molars: a contributing factor in mandibular fractures in contact sports Amer J Sports Med 1983, 11, 262-266

14 Chapman, P.J. Mouthguards and the role of sporting team dentists Aust Dent J 1989, 34, 36-43 